\title{
Dayak Onions (Eleutherine bulbosa (Mill.) Urb.) Bulbs Extracts Reduce the Blood Pressure of Ovariectomized Rats
}

\author{
Anton Bahtiar* and Delvika Yessi Chumala \\ Department of Pharmacology and Toxicology, Faculty of Pharmacy, Universitas Indonesia, Depok, Indonesia; \\ anton.bahtiar@ui.ac.id
}

\begin{abstract}
Background: Eleutherine bulbosa (Mill.) Urb. extract has eleutherinol that could bind with estrogen receptor alpha selectively, therefore it's a candidate for selective estrogen receptor modulator drugs. Objective: To determine the influence of $70 \%$ of ethanol extract of $E$. bulbosa (Mill.) Urb., bulbs on blood pressure of ovariectomized rats. Methods: To analyze the content of the E. bulbosa (Mill.) Urb., bulbs, thin layer chromatography of the extracts were performed using chloroform : methanol $(7: 1, \mathrm{v} / \mathrm{v})$ as the mobile phase. Thirty-six female Sprague-Dawley rats were used for this study, they were divided into six groups: SHAM and ovariectomized both given vehicle; tamoxifen (1.8 mg/ $\mathrm{kg} \mathrm{BW.)} \mathrm{as}$ the positive control; three doses of extract at 40,60 , and $90 \mathrm{mg} / \mathrm{kg}$ BW were administereted respectively. All groups were ovariectomized on day 1 , except the SHAM group. Measurement of blood pressure was performed on the day before ovariectomy, every week after ovariectomy until 28 days before treatment by the extract and then every week after treatment by the extract. Results: Three weeks after treatment of ovariectomized rats by the dose of $90 \mathrm{mg} / \mathrm{kg}$ BW of E. bulbosa (Mill.) Urb., extracts, could reduce the systolic blood pressure level to $28.06 \%$, the diastolic to $30.47 \%$. Conclusion: $70 \%$ of ethanolic extracts E. bulbosa (Mill.) Urb., could recover the blood pressure of ovariectomized rats, particularly at $90 \mathrm{mg} / \mathrm{kg}$.
\end{abstract}

Keywords: Blood Pressure, Dayak Onions, Eleutherinol, Naphthoquinone, Ovariectomized

\section{Introduction}

Menopause is a condition of the cessation of menstrual cycles in women due to decreased estrogen hormone production. Reduced estrogen levels lead to increased production of TNF- $\alpha$, so that osteoclast formation increases and osteoporosis develops. In the plasma lipid profile, estrogen levels are directly proportional to High-Density Lipoprotein (HDL). Moreover, inversely with the total cholesterol, triglycerides and Low-Density Lipoprotein (LDL) in plasma. In ovariectomized conditions, the total cholesterol, triglycerides, and LDL increase, while plasma HDL levels decrease. The increasing of lipid profile may increase the risk of atherosclerosis. The occurrence of atherosclerosis will also increase the risk of hypertension ${ }^{1,2}$.
Women who have menopause are prone to hypertension as a result of reduced estrogen hormone. Based on research conducted by the Joint National Committee (JNC 7), women who have postmenopause have a higher systolic pressure of $4-5 \mathrm{mmHg}$ than women who are still in premenopausal phase.

The most often applied therapy in treating postmenopausal symptoms is by using Hormone Replacement Therapy (HRT) which has agonist activity on all estrogen receptors in the body and is not selective, resulting in effects on unwanted organs such as breasts, and other reproductive organs ${ }^{3}$. The further treatment is by using Selective Estrogen Receptor Modulators (SERMs) that work agonists on receptors in non-reproductive organs and antagonists in reproductive organs. Examples of widely used SERMs are raloxifene and tamoxifen ${ }^{4}$. The 
ideal SERMs have anti-estrogen activity in the breast and endometrium, and estrogen activity can reduce the risk of osteoporosis and reduce total cholesterol, triglycerides, LDL, increase HDL, and improve cardiovascular function ${ }^{5}$. So it is encouraging to find an alternative treatment that has an ideal estrogenic effect, that is, agonists on estrogen receptors in non-reproductive organs and antagonists of estrogen receptors in the reproductive organs.

Dayak onion bulbs which are from the Iridaceae family, contain eleutherinol compounds which have been reported through in silico study that it can bind to estrogen receptors ${ }^{6}$. Considering the traditional use of this plant which has also been used to cure breast cancer, hypertension, diabetes mellitus, decreasing cholesterol, and stroke ${ }^{7}$, we studied Dayak onion bulbs as an alternative herb on the treatment of postmenopausal symptoms with parameters of blood pressure.

\section{Material and Methods}

\subsection{Chemicals and Reagents}

Dayak onion bulbs extracts was obtained from Indonesian Spice and Medicinal Crops Research Institute (BALITRO), Bogor, Indonesia. Tamoxifen was obtained from PT. Kalbe Farma, Indonesia, Lipid Reagents Kit was bought from DiaSys, Germany. Distilled water, ethanol 70\%, Carboxymethylcellulose (CMC), ether, and povidoneiodine was obtained from Brataco Chemical, Indonesia. Ketamine was obtained from MMC hospital, Jakarta.

\subsection{Plant Materials}

Dayak onion bulb as the primary material, was obtained from Palu, Central Sulawesi and authenticated by the Research Center for Natural resources of Tadulako University (No. 65/UN.28.UPT-SDHS/LK/2016). This plant was harvested from Palu forest in Central Sulawesi, Indonesia.

\subsection{Dayak Onion Bulbs Extract Preparation}

The Dayak onions were slices and were dried in an oven at $45^{\circ} \mathrm{C}$, and milled to powder. The extraction of dried powder of Dayak onions bulbs was done using $70 \%$ of ethanol by maceration. The rotary evaporator was used to concentrate extract.

\subsection{Eleutherinol Identification by TLC}

The sample $(10 \mu \mathrm{L})$ was spotted on a silica gel $60 \mathrm{~F} 254$ plates, and eluted by chloroform : methanol $(7: 1, \mathrm{v} / \mathrm{v})$ as the mobile phase. The elution process was performed until the mobile phase reaches the finish line. The spot then was identified using $10 \% \mathrm{KOH}$ in ethanol to find naphthoquinone derivate.

\subsection{Animals}

Pre-pubertal albino female Sprague-Dawley rats aged $28 \mathrm{~d}$ were purchased from Indonesia National Institute of Health Research and Development ${ }^{8}$. In the prepubertal rat, it is estimated that rats do not have a normal hormonal cycle that will affect the results ${ }^{8}$. Animals were grouped and maintained under standard laboratory conditions [room temperature] with $12 \mathrm{~h}$ dark and $12 \mathrm{~h}$ light cycle. The rats were allowed free access to a food and water. The experiment was approved and certified by the Ethics Committee of the Faculty of Medicine (44/ UN2.F1/Ethics/2017).

In this study, 36 female rats were divided into six groups. Group 1 is SHAM; group 2 to group 6 were ovariectomized and divided as follows: group 2 is a negative control group which received 0.5\% CMC; group 3 is a positive control group that received a dose of tamoxifen (1.8 mg/kg BW of rats); group 3, 4, and 5 are treatment groups which received $70 \%$ ethanolic extracts of E. bulbosa (Mill.) Urb., bulbs suspended in 0.5\% CMC with doses of $40 \mathrm{mg} ; 60 \mathrm{mg}$; and $90 \mathrm{mg} / \mathrm{kg} \mathrm{BW}$ of rats for $21 \mathrm{~d}$ respectively.

Estrous cycle was done before and after ovariectomy, to evaluate estrous cycle of rat. Pre-pubertal rat does not have estrous cycle. While pubertal rat has estrous cycle, this is similar with SHAM group. Ovariectomized rat does not have estrous cycle.

\subsection{Measurement of Blood Pressure}

Blood pressure measurements were performed with a non-invasive blood pressure gauge $\mathrm{CODA}^{\star}$ (Kent Scientific Corporation, USA), $\mathrm{CODA}^{\oplus}$ tail-cuff blood 
pressure system utilizes Volume Pressure Recording (VPR) sensor technology to measure the rat tail blood pressure. Ovariectomy would increase venous tone in the female Spontaneously Hypertensive Rat (SHR) via autonomic mechanisms 9 .

\subsection{Statistical Analysis}

All the data that get in this experiment was processes using statistics software for statistical analysis. The data represented the mean $\pm \mathrm{SD}$. To analyze the different between the group, One-way ANOVA followed by multiple comparison tests was used to analyze the difference in a group. A $p$-value of $<0.05$ was considered to be statistically significant.

\section{Results}

\subsection{Naphthoquinone Content Analysis}

The active component of Dayak onion bulb extract was confirmed by TLC, and the result is shown in Figure 1.

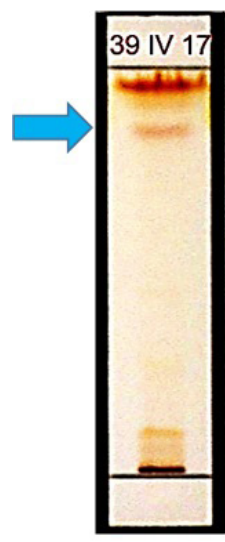

A

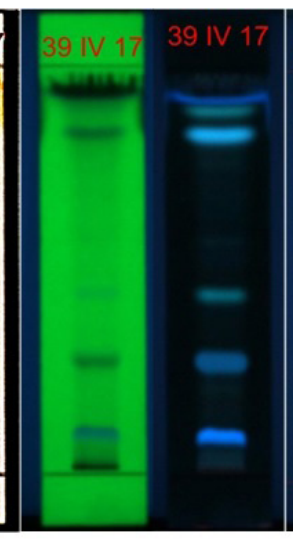

B
C

D
Figure 1. TLC of E. bulbosa extracts. The naphthoquinone (blue arrow) was identified by $0.5 \mathrm{~N} \mathrm{KOH}$ spray and given an orange band at the Rf 0.87 . (A) After sprayed by $0.5 \mathrm{~N} \mathrm{KOH}$ by visible. (B) Before spray by UV $254 \mathrm{~nm}$. (C) Before spray by UV $366 \mathrm{~nm}$. (D) After sprayed by $0.5 \mathrm{~N} \mathrm{KOH}$ by UV $366 \mathrm{~nm}$.

The spot corresponding to the extract gives a retardation factor of 0.87 . Identification of the TLC profile of ethanol extract $70 \%$ of Dayak onion bulbs showed six bands at $\mathrm{Rf}$ values $0.10,0.16,0.29,0.67$, 0.74 and 0.87 . The addition of $10 \% \mathrm{KOH}$ spray reagent in ethanol showed orange spot on TLC plate with Rf 0.87 as seen in Figure 1. This data indicated that the extract contained naphthoquinone derivate, eleutherinol.

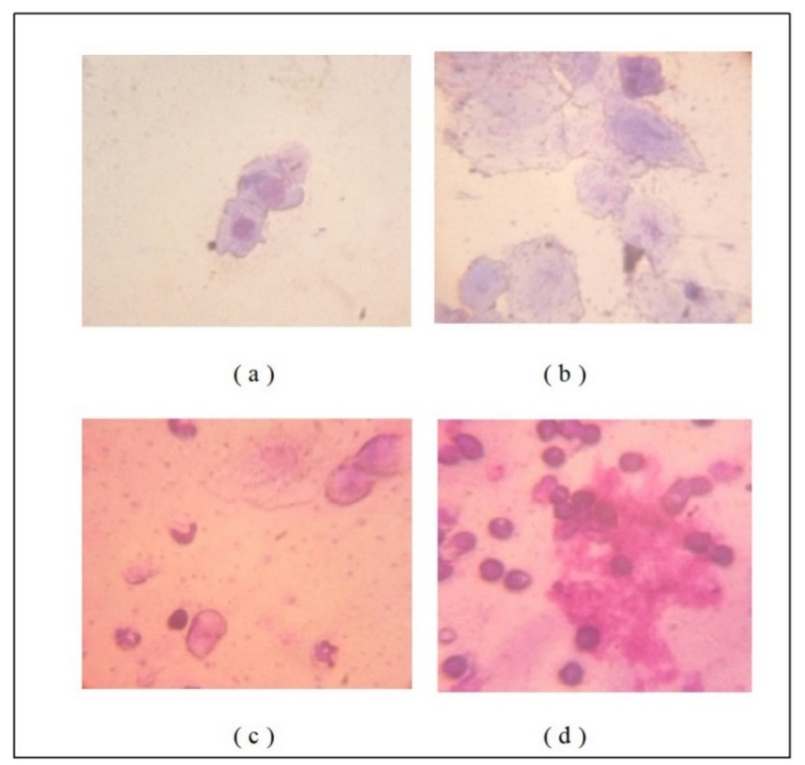

Figure 2. Evaluation of vaginal swabs of SHAM for an estrous cycle. Note: (a) Day 1 of the proestrous phase. (b) day 2 of the estrousphase. (c) Day 3 of the metestrus phase. (d) Day four diestrous phase. Observations were made at 40 $x$ magnification.

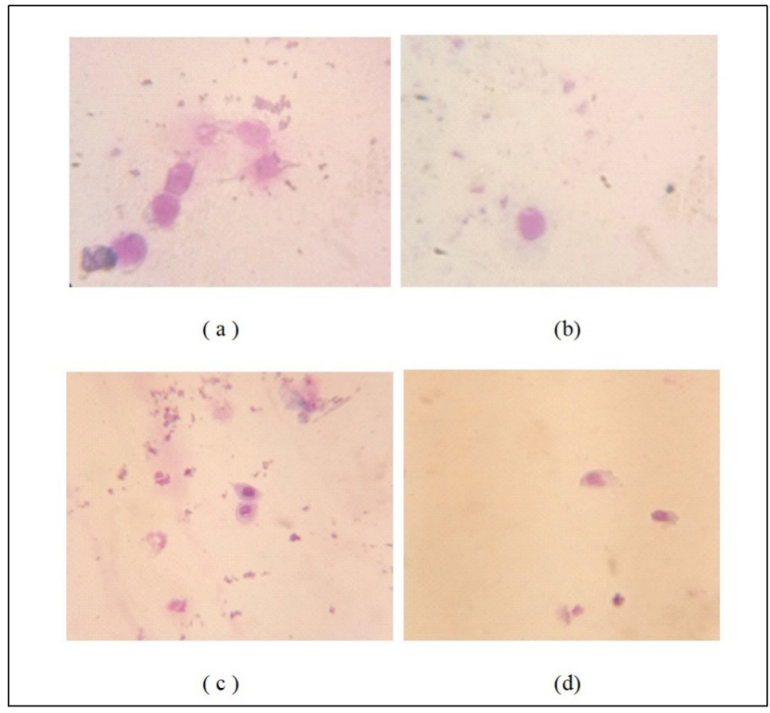

Figure 3. Evaluation of vaginal swabs of the ovariectomized group for the estrous cycle after ovariectomy. Note: Observation of the vaginal swab for four consecutive days of the ovariectomized group showed no difference in phases (a) day 1. (b) day 2. (c) day 3. (d) day 4. Observations were made at $40 x$ magnification. 


\subsection{Ovariectomy of Rats}

The evaluation of ovariectomy in the rats is as shown in Figure 2 to 4 . Figure 2 shows that in SHAM, the estrous cycle has 4 phase as a normal condition. This does not appear in ovariectomy rat as shown in Figure 3.

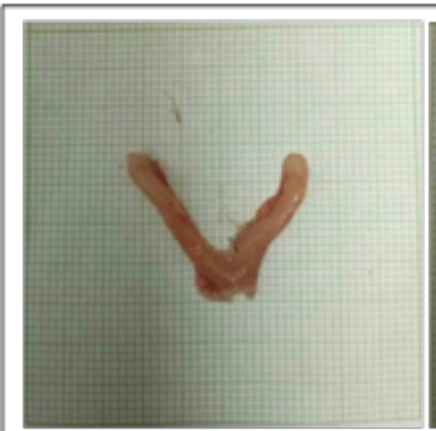

(a)

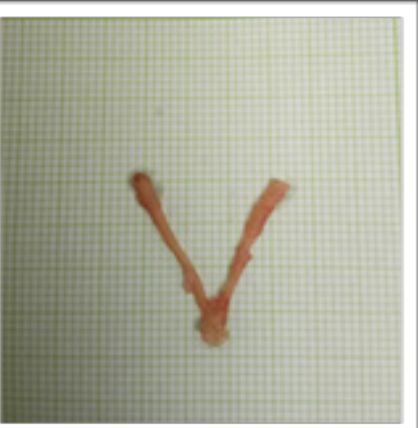

(b)
Figure 4. (a) The size of uterine of SHAM group. (b) Ovariectomized group.
The size and the weight of the uterus were recorded (Figure 4 and Table 1). The ovariectomized rat has smaller and lighter of uterus compared with SHAM group. This data indicates the confirmation of ovariectomy.

Table 1. The weight of uterine of SHAM group and ovariectomized group

\begin{tabular}{ccc}
\hline & $\begin{array}{c}\text { SHAM }(\mathbf{g}) \\
\text { Mean } \pm \text { SD }\end{array}$ & $\begin{array}{c}\text { OVX (g) } \\
\text { Mean } \pm \text { SD }\end{array}$ \\
\hline Uterine weight $(\mathrm{g})$ & $1.51 \pm 0.18$ & $0.34 \pm 0.03$ \\
Body weight gain $(\mathrm{g})$ & $35.58 \pm 11.35$ & $50.58 \pm 13.35$ \\
\hline
\end{tabular}

\subsection{The Effects of Dayak Onion Bulbs Extract on Blood Pressure}

The ovariectomy could have increased systolic and diastolic blood pressure, four weeks after ovariectomy systolic and diastolic blood pressure as compared with SHAM as shown in Table 2 and Tabel 3.

Table 2. The alteration of systolic pressure after three weeks of treatment

\begin{tabular}{lccc} 
& \multicolumn{2}{c}{ Systolic Pressure (mmHg) } & \multicolumn{2}{c}{ The decrease in systolic BP } \\
& Before & After & $-1.18 \pm 8.17$ \\
SHAM & $120.83 \pm 10.48$ & $114.67 \pm 4.93$ & $1.93 \pm 2.02$ \\
Negative control & $175.33 \pm 5.82^{*}$ & $169.67 \pm 5.12^{*}$ & $16.48 \pm 2.61$ \\
Positive control & $161.00 \pm 5.69^{*}$ & $141.17 \pm 1.60^{*}$ & $10.28 \pm 5.07$ \\
Dose I & $153.33 \pm 9.48^{*}$ & $139.00 \pm 4.56^{\#}$ & $19.43 \pm 4.13$ \\
Dose II & $159.33 \pm 2.73^{*}$ & $133.00 \pm 1.67^{\#}$ & $28.06 \pm 5.66$ \\
Dose III & $164.67 \pm 5.89^{*}$ & $123.17 \pm 4.83^{\#}$ & 2 \\
\hline
\end{tabular}

Note: $\mathrm{SHAM}=\mathrm{CMC} 0.5 \%$, negative control $=\mathrm{CMC} 0.5 \%$, positive control = tamoxifen $0.36 \mathrm{mg} / 200 \mathrm{~g}$ BW, Dose I =E. bulbosa extracts bulb $8 \mathrm{mg} / 200 \mathrm{~g} \mathrm{BW}$, Dose II = $12 \mathrm{mg} / 200 \mathrm{~g} \mathrm{BW}$, Dose III $=18 \mathrm{mg} / 200 \mathrm{~g} \mathrm{BW},\left(^{*}\right)=p<0.05$ compared with SHAM, $(\#)=p<0.05$ compared with OVX.

Table 3. The alteration of diastolic pressure after three weeks of treatment

\begin{tabular}{lccc}
\hline \multicolumn{1}{c}{ Groups } & \multicolumn{2}{c}{ Diastolic Pressure $(\mathrm{mmHg})$} & The decrease in diastolic \\
& Before & After & $-17.60 \pm 18.95$ \\
SHAM & $73.83 \pm 9.11$ & $87.67 \pm 8.16$ & $7.26 \pm 10.80$ \\
Negative control & $130.00 \pm 27.28^{*}$ & $141.33 \pm 14.29^{*}$ & $15.94 \pm 10.85$ \\
Positive control & $125.17 \pm 15.84^{*}$ & $119.83 \pm 8.23^{\#}$ & $7.11 \pm 26.31$ \\
Dose I & $126.00 \pm 16.54^{*}$ & $111.17 \pm 8.68^{\#}$ & $8.22 \pm 12.88$ \\
Dose II & $127.67 \pm 16.07^{*}$ & $115.50 \pm 2.51^{\#}$ & $30.47 \pm 13.82$ \\
Dose III & $132.67 \pm 10.69^{*}$ & $91.83 \pm 12.32^{\#}$ & \\
\hline
\end{tabular}

Note: SHAM $=$ CMC 0.5\%, negative control $=$ CMC 0.5\%, positive control = tamoxifen $0.36 \mathrm{mg} / 200 \mathrm{~g}$ BW, Dose I =E. bulbosa extracts bulb $8 \mathrm{mg} / 200 \mathrm{~g} \mathrm{BW}$, Dose II $=12 \mathrm{mg} / 200 \mathrm{~g} \mathrm{BW}$, Dose III $=18 \mathrm{mg} / 200 \mathrm{~g} \mathrm{BW},\left(^{*}\right)=p<0.05$ compared with SHAM, (\#) $=p<0.05$ compared with OVX. 
There was a significant difference in systolic blood pressure between extract treatment group and negative control group at one week after treatment while there was no significant difference between diastolic blood pressure between the treatment group and negative group. There was a difference in both systolic and diastolic blood pressure after two weeks of treatment compared to a condition before treatment. The result on Table 2 and Table 3 showed that in the third week after treatment there was no significant difference in systolic and diastolic blood pressure between the groups given Dayak bulb extract $(90 \mathrm{mg} / \mathrm{kg})$ and SHAM group.

\section{Discussion}

\subsection{Analysis of Naphthoquinone by Thin Layer Chromatography}

The TLC method successfully identified the content of the Dayak onion extracts. Naphthoquinone was separated by methanol : chloroform $(7: 1, \mathrm{v} / \mathrm{v})$ and identified by chromogenic spray of $0.5 \mathrm{~N}$ Potassium hydroxide ${ }^{8}$. When sprayed with alcoholic potassium hydroxide, the green fluorescence changed to an orange fluorescence.

\subsection{Analysis of Blood Pressure}

At one week after treatment there was a significant difference in systolic pressure between Dayak onion bulbs extract and OVX, while there was no significant difference in diastolic pressure between Dayak onion bulbs extract and OVX. Both systolic and diastolic pressure in the treatment group had a significant difference ( $p<0.05)$ with the SHAM at two weeks after treatment. In the third week after treatment, there was no significant difference in systolic and diastolic blood pressure between the groups treated by Dayak onion bulbs extract $(90 \mathrm{mg} / \mathrm{kg})$ and SHAM. This suggests that administration of $90 \mathrm{mg} / \mathrm{kg}$ dose of Dayak onion bulb extract could lower both systolic and diastolic blood pressure to normal blood pressure after three weeks of treatment.Ovariectomized made blood pressure increases due to an increase in vasoconstrictor NPY and decrease of vasodilator neuropeptides ${ }^{10}$.

Furthermore, the decrease in blood pressure both systolic and diastolic occurred due to the presence of eleutherinol compounds contained in bulbs extract of Dayak onions which are estrogen agonist. The decreasein blood pressure was thought to be due to a decrease in blood lipid profile, preventing atherosclerosis and decreasing blood pressure inovariectomized $\mathrm{rat}^{11}$.

\section{Conclusion}

The $70 \%$ ethanolic extract of Dayak onion bulbs could reduce blood pressure by reducing lipid profile of ovariectomized model rat, particularly at $90 \mathrm{mg} / \mathrm{kg}$.

\section{Acknowledgement}

This research was support by Directorate Research and Community Service, Universitas Indonesia 2017.

\section{Reference}

1. Mieszczanska HZ, Velarde GP. Management of cardiovascular disease in women. Springer-Verlag Berlin Heidelberg; 2014. Crossref.

2. Hargrove GM, Junco A, Wong NCW. Hormonal regulation of apolipoprotein AI. Journal of Molecular Endocrinology. 1999; 22:103-11. Crossref. PMid:10194513

3. Goodman NF, Corbin RH, Ginzburg SB, Katz IA, Woode DE. AACE medical guidelines for clinical practice for the diagnosis and treatment of menopause. Endocrine Practice. Official Journal of the American College of Endocrinology and the American Association of Clinical Endocrinologists. 2011; 17(Suppl 6):1-25. Crossref.

4. Pinkerton, JV, Thomas S. Use of SERMs for treatment in postmenopausal women. Journal of Steroid Biochemistry and Molecular Biology. 2014; 142:142-154. Crossref.

5. Amelia T, Pratiwi D, Romsiah, Tjahjono D. In Silico study of the component of Eleutherine americana MERR on human estrogen receptor alpha as potential anti-breast cancer. $3^{\text {rd }}$ International Conference on Computation for Science and Technology (ICCST-3); 2014. 
6. Galingging R. Dayak onion as a multifunctional medicinal plant. Bulletin on Research and Development of Industrial Plants in Central Kalimantan. 2009; 15(3):16-8.

7. Kotakemori M, Okada K. Thin-layer chromatography of some substituted naphthoquinones. Agricultural and Biological Chemistry. 1966; 1369(Mar):2-4. Crossref.

8. Govoni KE, Wergedal JE, Chadwick RB, Srivastava AK, Mohan S. Prepubertal OVX increases IGF-I expression and bone accretion in C57BL/6J mice. American Journal of Physiology- Endocrinology and Metabolism. 2008; 295(5):E1172-80. Crossref.

9. Douglas SM, Rebecca R, Vogel E, Mark C, Eyster KM. Effect of ovariectomy on blood pressure and venous tone in female spontaneously hypertensive rats. American Journal of Hypertension. 2008; 21(9):983-8. Crossref. PMid:18636067

10. Di Carlo C, Sardo ADS, Bifulco G, Tommaselli GA, Guerra G, Rippa E, Nappi C. Postmenopausal ovariectomized increases vasoconstrictor neuropeptides and decreases vasodilator neuropeptides content in arterial-wall autonomic terminations. Fertility and Sterility. 2007; 88(1):95-9. Crossref.

11. Radwanska E. The role of reproductive hormones in vascular disease and hypertension. Steroids. 1993; 58(12):605-10. Crossref. 